this reason, a search for diclonal 'gammopathies' in males might be more rewarding than in females.

There seem to be at least three possible origins of diversity : (1) accelerated replacement of single nucleotide pairs as suggested here; (2) intra-cistronic inversions, duplications or deletions as suggested by Smithies; (3) a process equivalent to transformation in bacteria in which the replacing segment of DNA may come either from within the cell or from an active adjacent cell. When further variable chains have been examined for sequence it should become possible seriously to consider these alternatives.

${ }^{1}$ Burnet, F. M., The Clonal Selection Theory of Acquired Immunity (Vanderbilt and Cambridge Univ. Presses, 1959).

${ }^{2}$ Cohen, S., and Porter, R. R., Adv. in Immunol., 4, 287 (1964).

Edelman G. M., and Gally, J. A., Proc. U.S. Nat. Acad. Sci., 51, 846 (1964),

4 Fleischman, J. B., Porter, R. R., and Press, E. M., Biochem. J., 88, 220 (1963).

${ }^{5}$ Hilschmann, N., and Craig, L. C., Proc. U.S. Nat. Acad. Sci., 53, 1403 (1965).

- Rosevear, J. W., and Smith, E. I., J. Biol. Chem., 236, 425 (1961).

'Schwartz, J. H., and Edelman, G. M., J. Exp. Med.,118, 41 (1963).

- Milstein, C., Nature, 209, 370 (1966). "Titani, K., Whitley, E., Avogardo, L., and Putnam, E. W., Science, 149,
1090 (1965).

${ }^{30}$ Milstein, C., Nature, 205, 290 (1965).

$"$ Baglioni, C., Carbonara, A., Cioli, D., and Alescio, Z., Science (in the press).

${ }^{12}$ Meltzer, M., Franklin, E. C., Fudenberg, H., and Fragione, B., Proc. U.S. Nat. Acad. Sci., 51, 1007 (1964).
${ }^{13}$ Franklin, E. C., Lowenstein, J., Bigelow, B., and Meltzer, M., Amer. I. Med., 37, 332 (1964).

${ }^{14}$ Franklin, F. C., J. Exp. Med., 120, 691 (1964)

${ }^{15}$ Frangione, B., and Franklin, E. C., J. Exp. Med.,122, 1 (1965).

Nisonoff, A., in Conceptual Advances in Immunology and Oncology, 373

Hong, R., Palmer, J. L., and Nisonoff, A., J. Immunol., 94, 603 (1965).

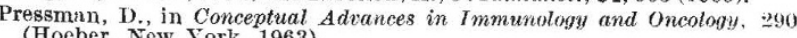
1963).

${ }^{19}$ Franek, F., and Nezlin, R. S., Folia Microbiol. (Praha), 8, 128 (1963).

${ }^{20}$ Roholt, O. A., Radzimski, G., and Pressman, D., Science, 148, 613 (1965).

${ }^{1}$ Roholt, 0. A., Radzimski, G., and Pressman, 1., f. Exp. Med., 122, 785 (1965).

22 Metzger, H., and Mannik, M., J. Exp. Med.. 120, 765 (1964).

${ }^{23}$ Grossberger, A. L., Radzimski, G., and Pressman. D.. Biochemistiry, 1, 391 (1962).

${ }^{24}$ Roholt, O. A., Grossberger, A. L., and Pressman, 1)., Sciene, 141, 726 (1963).

${ }^{25}$ Metzger, H., Wofsy, L., and Singer. S. J., Pror. I.S. Nat. Arad. Sci., 51 612 (1964).

${ }^{26}$ DoolittJe, R. F., and Singer, S. J., Proc. U.S. Nat. Acad. Sci. (in the press) (personal communication).

27 Porter, R. R., Brit. Med. Bull., 19, 197 (1963).

${ }^{28}$ Grey, H. M., Immunology, 7, 82 (1964).

29 IIershey, A. D., Genetics, 31, 620 (1946)

${ }^{30}$ Benzer, S., Proc. U.S. Nat. Acad. Sci., 48, 403 (1961).

${ }^{31}$ Zuckerkandl, E., and Pauling, L., in Evolving Genes and Proteins, edit. by Bryson, Vogel, 97 (Academic Press, New York, 1965).

32 Margoliash, L., and Smith, E. L., in Evalving Genes and Proteins, edit. by Bryson, Vogel, 221 (Academic Press, New York, 1965).

${ }^{33}$ Jukes, T. H., in Evolving (Genes and Proteins, edit. by Bryson, Vogel, 200 (Academic Press, New York, 1965).

\title{
INTENSITY OF THE GEOMAGNETIC FIELD IN INDIA OVER THE PAST 4,000 YEARS
}

\author{
By R. N. ATHAVALE \\ Tata Institute of Fundamental Research, Colaba, Bombay 5
}

$\mathrm{B}^{\mathrm{A}}$ AKED bricks and pots acquire magnetization as they cool from the high temperatures prevailing inside kilns and hearths to normal temperatures. This effect can be detected later, when it is termed 'thermoremanent magnetization'. The magnetization is in the direction and proportional to the ambient magnetic field of the Earth at the time of firing. Folgheraiter ${ }^{1}$ and Koenigsberger ${ }^{2}$ suggested that such materials obtained from ancient (archaeological) sites could be used for studying the Earth's past magnetic field. Such an application had to await the development of a satisfactory technique for studying detailed variation in field-strength itself. This was achieved by Thellier et $a l .{ }^{3}$, who compared ancient remanent magnetization in brick samples with that acquired when these samples were heated and cooled in the present magnetic field. This pioneering work led to the interesting observation that 2,000 years ago, the Earth's magnetic field in France was about 60 per cent stronger than it is at present.

In view of the importance of this result to geomagnetic studies and other allied fields, it was considered desirable to conduct similar studies in other areas. India has a geomagnetic latitude spread of $0^{\circ}-25^{\circ} \mathrm{N}$. and also has a large number of archaeological sites, many of which have recently been dated by the Radiocarbon Laboratory at this Institute. In view of these considerations, the present study was undertaken.

The method used was, in principle, the same as that of Thellier et al. ${ }^{3}$, who mainly used bricks for the purpose. The materials most commonly obtained from archaeological excavations are, however, pots and potsherds. In order to make use of these, a suitable technique had to be devised. Small pieces of pottery or brick were firmly embeddod in plaster of Paris inside individual cylindrical porcelain containers (height, $4 \mathrm{~cm}$; diameter, $4 \mathrm{~cm}$ ). With their orientation thus fixed, the magnetic moment of the sample was measured by means of an astatic magnetometer (sensitivity, $10^{-5}$ gauss). Fach sample was first rotated below the magnetometer along the axis of the cylinder ( $Z$ component) and the directions of maximum ( $X$-direction) and minimum ( $Y$-direction) deflexion determined. Proper reference marks were then made and the deflexions along the $X, Y$ and $Z$ co-ordinates measured by the standard procedure which involved making a correction for sample inhomogeneity. The sample concerned was then heated to $300^{\circ}-400^{\circ} \mathrm{C}$ with the $X$-direction aligned with the meridian, cooled and its magnetization remeasured. The sample was then reheated to the same temperature in reverse orientation, cooled and the magnetization measured again. These measurements enable us to obtain partial thermoremanent magnetization in ancient and laboratory fields by addition and subtraction of the vector co-ordinates $X, Y$ and $Z$ in the manner suggested by Thellier ${ }^{3}$. The sample was further heated to $675^{\circ} \mathrm{C}$ (which is the Curie point for haematite), cooled and its magnetization remeasured. This enabled us to deduce another value for the ratio of the ancient field strength to the present one.

The samples were heated in a non-inductive portable furnace. The heating elements were constructed from 22 gauge platinum wire, wound around quartz tubes with the lead wire of each element passing through the centre of the tube in a direction opposite to that of winding4. Ten such elements were mounted symmetrically inside a cement pipe (diameter, $22.5 \mathrm{~cm}$; height, $13 \mathrm{~cm}$ ). A thick copper vessel (diameter, $16.5 \mathrm{~cm}$; height, $7.5 \mathrm{~cm}$ ) was placed co-axially inside the furnace. Four samples were heated simultaneously inside this vessel in nitrogen atmosphere. A duplicate assembly made it possible to use the furnace to heat one set of samples while the other set cooled.

The precision of the experimental procedure was determined in the following way. A single pot was heated to $1,000^{\circ} \mathrm{C}$ in an oxidizing atmosphere for $2 \mathrm{~h}$ in order to destroy initial magnetization and to ensure that the constituent minerals remained stable during subsequent heatings, and then allowed to cool. In this way it acquired 


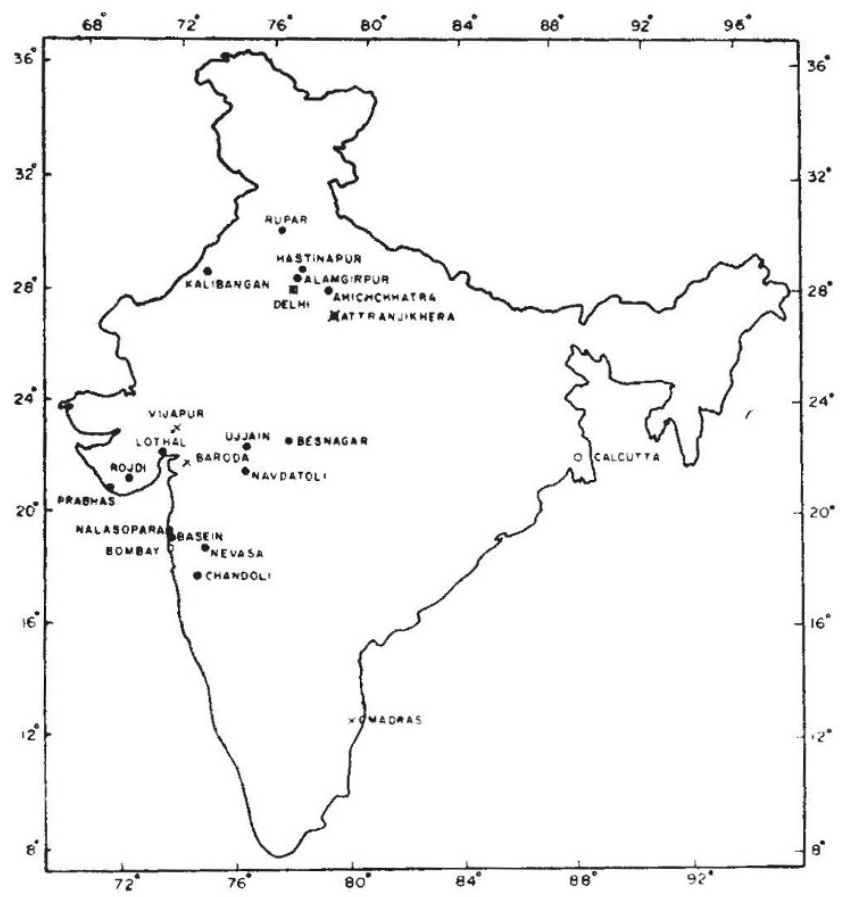

Fig. 1. Map of India showing sample collection sites. $\times$, Modern samples; archacological samples

a magnetization corresponding to the laboratory field. Four pieces of this pot were then run through the experimental cycle already described. The ratio of the two magnetizations in the laboratory fiold thus determined should theoretically be $\mathrm{I} \cdot 00$; the average of eight values deduced from the experiment was $1 \cdot 03$. The scatter in the values corresponded to a standard deviation of 9 per cent, which may be taken as an indication of the magnitude of the overall error of the measurements.

\section{Results on Modern Samples}

The basic assumption made in all such archaeomagnetic intensity studies is that the thermoremanent magnetization acquired by baked bricks and pots is proportional to the strength of the Earth's ambient field at the time of firing and that it does not change afterwards. In order to verify the first part of this assumption, we collected samples of modern pottery from five different localities and ran them through the experimental procedure already described. Fig. 1 shows the localities whence the modern samples were collected. Table 1 gives the field strength at the various sites as determined experimentally from measurements on modern pottery and also the value derived from the co-ordinatos of the sites from data reported by Vestine et al. ${ }^{5}$ for 1945 and extrapolating them to 1963. Bearing in mind that the actual field at the site of the hearth could be different from the extrapolated value by a few per cent, agreement between the extrapolated values and the experimental ones (within a standard deviation) is quite satisfactory. This indicates that the method is effective for modern pottery. Our procedure involved the determination of intensity ratios at only two temperatures; however, the elaborate method adopted by Thellier et $a l .^{3}$ involved measurement of ratios at a serics of temperatures, thereby making possible more

\begin{tabular}{|c|c|c|c|c|c|}
\hline Site & $\begin{array}{c}\text { Table } 1 . \\
\text { Geo- } \\
\text { graphical } \\
\text { lat. N. }\end{array}$ & $\begin{array}{c}\text { RESULTS } \\
\text { Co-or- } \\
\text { dinates } \\
\text { long. E. }\end{array}$ & $\begin{array}{l}\text { No. of } \\
\text { samples }\end{array}$ & $\begin{array}{l}\text { Experimental } \\
\text { value of } \\
\text { field (G) }\end{array}$ & $\begin{array}{l}\text { Caleulated } \\
\text { value of } \\
\text { field (G) }\end{array}$ \\
\hline Delhi & $28^{\circ} 35^{\prime}$ & $77^{\circ} 12^{\prime}$ & 8 & $0.458 \pm 0.045$ & 0.478 \\
\hline Attranjikhera & $27^{\circ} 42^{\prime}$ & $78^{\circ} 44^{\prime}$ & 4 & $0.461 \pm 0.086$ & $0 \cdot 474$ \\
\hline Vijapur & $23^{\circ} 30^{\prime}$ & $72^{\circ} 40^{\prime}$ & 4 & $0.435 \pm 0.020$ & $0 \cdot 447$ \\
\hline Baroda & $22^{\circ} 10^{\prime}$ & $73^{\circ} 37^{\prime}$ & 4 & $0.437 \pm 0.030$ & $0 \cdot 445$ \\
\hline Madras & $13^{\circ}$ & $80^{\circ}$ & 8 & $0.428 \pm 0.031$ & 0.413 \\
\hline
\end{tabular}

accurate determinations. The precision of our procedure is, however, quite adequate for detecting any variation of large magnitude such as has been observed by other workers $^{3,6}$.

\section{Criterion for Stability of Magnetization of Samples}

Only perfectly baked red ware giving a good metallic sound was chosen for the work. Samples showing grey core or giving a dull note when struck were not used, as it was considered that these would most likely contain unstable magnetic minerals. The baking temperature for material thus selected is generally above $700^{\circ} \mathrm{C}$ and it can be assumed, therefore, that samples chosen on this basis had acquired their thermoremanent magnetization over the entire range of temperature from $675^{\circ} \mathrm{C}$ (the highest Curie temperature - that of haematite) to the environmental temperature to which they cooled.

For each sample, we obtained two values for the ratio of ancient to laboratory field expressed in terms of the magnetization acquired by the sample; one for an intermediate temperature (partial thermoremanent magnetization) and one for the Curie temperature. In order to ensure that the magnetic minerals in the ancient samples had not undergone any chemical change during the reheating process in the laboratiory, a comparison was made between the two ratios. Any archaeological sample the ratio of which differed by more than 30 per cent was considered to contain an excessive amount of unstable minerals and was rejected. Such samples formed only about 15 por cent of the measured samples.

\section{Results on Archaeological Samples}

Fig. 1 shows the location of archaeological sites whence the samples were obtained. Table 2 gives the results of magnetic measurements and other pertinent data for these samples. The "ages" of the samples are based on radiocarbon dates and archaeological evidence.

The ratios of the ancient to present fields at the sites, averaged from a set of samples, are given in the final column; the errors quoted are one standard deviation, which indicates the magnitude of scatter in the results. The present field at the sites was estimated by first making use of tables compiled by Vestine et al. ${ }^{5}$ for 1945 and then correcting the value given to the 1963 one by a factor obtained from 1963 and 1945 values at the Bombay Magnetic Observatory. In Fig. 2 the values deduced for the intensity (normalized to Bombay) are plotted. A considerable random scatter in the data is obvious and no

Table 2. Results on ARChazological Samples

\section{Site}

(1) Alamgirpur (2) Basein Fort 3) Hastinapur (4) Attranjikher (5) Ahichechntra (6) Ahichch

(7) Rupar

(8) Ahichchhtra (9) Ahichchhtra (10) Ahichchht (12) Nevasa (13) Attranjikher (14) Ujjain (15) Nalasopara (16) Iastinapur (17) Hastinapu (18) Besnagar (19) Ahichchhtra (20) Hastinapur (21) Hastinapur (22) Attranjikhe (23) Chandol (24) Prabhas (25) Navada (26) Lotha (27) Kalibangan (28) Rojdi (29) Kalibangan (30) Kalibangan

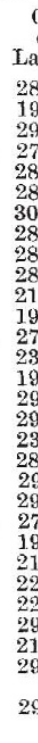

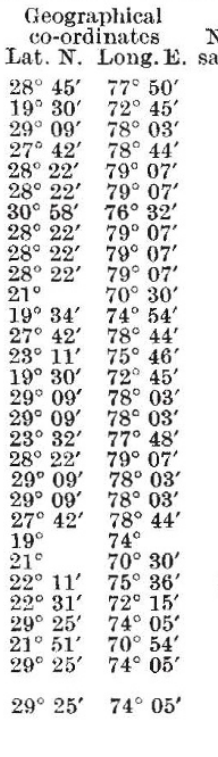

$\begin{array}{cc}\begin{array}{c}\text { Age } \\ \text { (before } \\ \text { present) }\end{array} & \begin{array}{c}\text { Ancient/present } \\ \text { fields at } \\ \text { site }\end{array} \\ 350 \pm 200 & 0 \cdot 82 \pm 0 \cdot 06 \\ 420 \pm 10 & 1 \cdot 00 \pm 0 \cdot 06 \\ 700 \pm 50 & 0 \cdot 96 \pm 0 \cdot 12 \\ 900 \pm 150 & 0 \cdot 85 \pm 0 \cdot 07 \\ 975 \pm 125 & 0 \cdot 87 \pm 0 \cdot 08 \\ 1150 \pm 50 & 0 \cdot 87 \pm 0 \cdot 04 \\ 1500 \pm 150 & 0 \cdot 81 \pm 0 \cdot 07 \\ 1550 \pm 50 & 0 \cdot 78 \pm 0 \cdot 08 \\ 1725 \pm 125 & 0 \cdot 76 \pm 0 \cdot 04 \\ 1850 \pm 100 & 0 \cdot 76 \pm 0 \cdot 08 \\ 1800 \pm 150 & 0 \cdot 97 \pm 0 \cdot 12 \\ 2000 \pm 100 & 0 \cdot 91 \pm 0 \cdot 08 \\ 2000 \pm 150 & 0 \cdot 77 \pm 0 \cdot 11 \\ 2150 \pm 100 & 0 \cdot 88 \pm 0 \cdot 04 \\ 2200 \pm 25 & 1 \cdot 16 \pm 0 \cdot 11 \\ 2200 \pm 100 & 0 \cdot 86 \pm 0 \cdot 07 \\ 2300 \pm 100 & 1 \cdot 00 \pm 0 \cdot 09 \\ 2300 \pm 100 & 0 \cdot 90 \pm 0 \cdot 04 \\ 2300 \pm 100 & 0 \cdot 80 \pm 0 \cdot 08 \\ 2400 \pm 100 & 0 \cdot 88 \pm 0 \cdot 07 \\ 2500 \pm 100 & 0 \cdot 79 \pm 0 \cdot 07 \\ 2975 \pm 100 & 0 \cdot 99 \pm 0 \cdot 24 \\ 3000 \pm 100 & 0 \cdot 89 \pm 0 \cdot 20 \\ 3350 \pm 100 & 0 \cdot 87 \pm 0 \cdot 07 \\ 3600 \pm 100 & 0 \cdot 91 \pm 0 \cdot 10 \\ 3800 \pm 100 & 0 \cdot 93 \pm 0 \cdot 13 \\ 3800 \pm 100 & 0 \cdot 75 \pm 0 \cdot 05 \\ 3900 \pm 100 & 0 \cdot 70 \pm 0 \cdot 12 \\ 4200 \pm 100 & 0 \cdot 80 \pm 0 \cdot 07 \\ & \\ 4200 \pm 100 & 0 \cdot 67 \pm 0 \cdot 06 \\ & \end{array}$




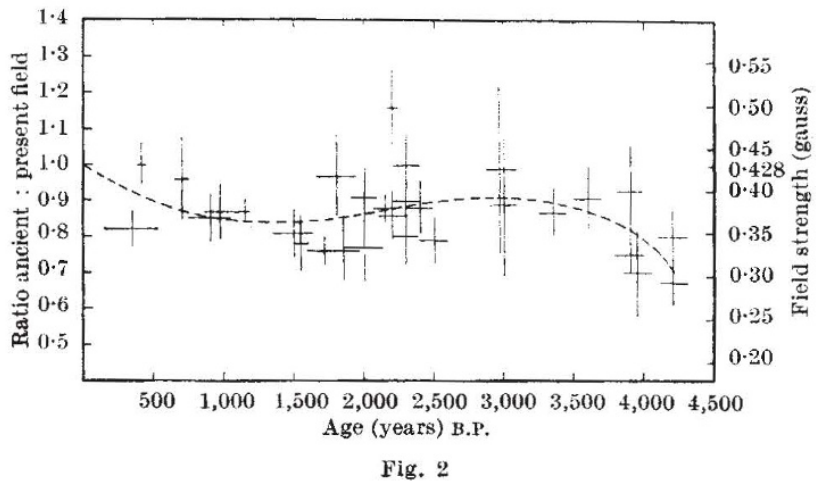

marked secular variation is indicated. The data show, however, that in the past the field intensity was smaller by about 15 per cent.

We have also drawn a continuous curve through the points based on a least square analysis. If this is seriously considered it may be taken to indicate that the ancient mean field strength over India was about 15 per cent lower than the present 1,300 years ago, about 10 per cent lower 3,000 years ago, and about 30 per cent lower 4,000 years ago.

In determining the intensity ratios we have not taken into account any viscous magnetization which the samples might have acquired since they were first baked. It is known, however, from previous investigations that the magnitude of the error arising from this effect is quite small. Thellier et al. ${ }^{3}$ have reported that out of the nine different sites selected by them, samples of baked earth from eight had secondary magnetization which was between 0.2 and 2 per cent of the initial magnetic moment. In samples from only one site the contribution due to this factor was $4 \cdot 6$ per cent. It is, therefore, safe to assume that accounting for the effect of viscous magnetization would not significantly alter the results presented here as they were obtained with a technique which had a precision of \pm 9 per cent.

\section{Discussion}

Results of archacomagnetic intensity obtained so far can be divided into three categories:

(1) The French ${ }^{3}$ and Russian ${ }^{6}$ results on baked bricks and clay; these show a gradual increase in the field intensity in the past with a peak value of $1 \cdot 6$ times the present value for 2,000-year-old samples and before this a decline to a value almost the same as at present for 4,600-year-old samples.

The measurements of Thellier et $a l .^{3}$ were made on oriented samples so that the inclination of the field at the time the bricks were fired could also be measured, and a correction made for the measured intensity in order to allow for any variation in inclination with respect to the present one. The application of such a correction changes the absolute value of field-strength by as much as 10 per cent in some of their results.

(2) The Japanese results ${ }^{6}$ on basalts and baked pottery; these show the present intensity for 1,000-ycar-old samples, a sharp increase by a factor of 1.5 for approximately 2,000-year-old basalt samples, and an equally sharp decline to present value for 3,000-year-old samples.

The results on basalts, which contain complex mineralogical constituents, are usually considered less reliable for estimating ambient field strength. Furthermore, these results were for unoriented samples, and were not corrected for any changes in intensity brought about by any secular variation in inclination of the field. Watanaber has carried out extensive work on this aspect in Japan on samples as old as 6,000 years and finds the range of secular variation of inclination to be between $40^{\circ}$ and $60^{\circ}$ around a mean value of $50^{\circ}$. DuBois ${ }^{8}$ reports a similar spread of values between $40^{\circ}$ and $60^{\circ}$ for the first millennium of the Christian era, for samples from the south-western United States. Using the formula $F^{\prime}=\frac{2 M}{R^{3}\left(1+3 \cos ^{2} I\right)^{\frac{1}{2}}}$ (where $F$ is the field intensity at the site, $I$ is the inclination, and $M$ and $R$ are the magnetic moment and radius of the Earth), and taking the extreme values of $40^{\circ}$ and $60^{\circ}$ and average value of $50^{\circ}$ for the inclination in Japan, it can be seen that the uncertainty in the estimation of intensity values due to this cause could be as much as \pm 12 per cent.

(3) Indian results on baked pottery and brick samples over the past 4,000 years show that the average field was not much different from the present--in fact lower only by about 15 per cent. These results are also for unoriented samples, and for reasons already discussed they may show variation in field intensity to the extent of \pm 8 per cent due to possible variation in inclination (the present inclination in this region is about $25^{\circ}$ ).

There are obvious discrepancies between the three groups of data if the variation is considered to be global in scale. All three results can, however, he reconciled if they depict regional phenomena. Magnetic observatory records over the past 100 years tend to support this contention. They show that the intensity at the Indian and other South East Asian stations has been increasing while that at the European stations has been decreasing. It seems, therefore, that definite conclusions regarding the absolute variation of the dipole moment, averaged over the world, can be made only after data from many other regions are available.

On the other hand, recent measurements of the variation in the activity of carbon-14 produced by cosmic rays over the past few thousand years indicate that some changes in the dipole moment have probably occurred. Damon et al. ${ }^{8}$ measured the activity of carbon-14 in a number of tree-rings and historically dated wood samples. They found the variation, $\Delta{ }^{14} \mathrm{C}$, small ( $+1-2$ per cent) as far back as 2,000 years B.P., and a systematic increase in the carbon- 14 content in the more distant past with a gradient of about 0.4 per cent per century. They give a $\Delta{ }^{14} \mathrm{C}$ value of about +7 per cent for a 4,600 -year-old (historical date) Egyptian sample. Recently, Schell ${ }^{10}$ has made similar observations based on studies on tree-rings going back 3,100 years. He has also summarized other available data in carbon-14 variation and has shown that they follow the same general trend as already discussed here. If we assume that the variation in carbon-14 activity is mainly caused by changes in the dipole moment, then the increase in radiocarbon production before 2,000 years B.P. would require the average strength of the Earth's magnetic field to be lower than its present value. This is in qualitative agreement with our magnetic data, if they are considered on a global scale.

I thank Prof. D. Lal for his guidance in this work, Dr. Rama for valuable criticism of the manuscript, and Prof. K. R. Ramanathan, D. P. Agarwal, C. Radhakrishnamurthy and P. W. Sahasrabudhe for helpful discussions. I also thank Shri A. Ghosh and other officers of the Archaeological Survey of India and H. D. Sankalia, J. M. Nanavati, R. C. Gaur and others for generously providing samples, and E. Noronha and A. S. Tamhane for assistance in the measurements and computations.

' Folgheraiter, G., J. de Physique, 8, 660 (1899).

'Koenigsberger, J., Terr. Magn. Atmos. Elec, 43, 119 and 299 (1938).

${ }^{3}$ Thellier, E., and Thellier, 0., Ann. de Geophys., 15, 288 (1959).

Athavale, R. N., Radhakrishnamurthy, C., and Sahasrabudhe, P. W. Geophy. J. Roy. Astro. Soc., 7, 304 (1963).
G.

Vestine, E. H., Laporte, I., Cooper, C., Lange, I., and Hendrix, W. C. Carnegie Inst. Wash., 462 (1948).

- Nagata, T., Arai, Y., and Momose, K., J. Geophys. Res., 68, 5277 (1963).

Watanabe, N., Nature, 182, 388 (1958).

'DuBois, R. L., Trans, Amer. Geophys. Union, 46, 64 (1965).

'Damon, P. E., and Long, A., Thirteenth Intern. Uni. Geodesy and Geophys., Berkeley (1963).

Schell, W. R., thesis, Univ, Washington (1963). 